\title{
Pure agraphia: a discrete form of aphasia
}

\author{
G. R OS A T I A N D P. DE B A S T I A N I \\ From the Neurological Clinic of the University of Ferrara, Ferrara, Italy
}

SUMMARY A 62 year old, right handed man developed a pure agraphia as the result of a left temporal lobe stroke. Isolated writing disturbances persisted for seven months until he had a second cerebrovascular accident resulting in total aphasia and right hemiplegia. A CAT scan obtained four months after the first episode showed a localised dilatation of the posterior portion of the left Sylvian cistern and patchy areas of low absorption in the left temporal lobe. The report supports suggestions that localised damage to the language area can produce a pure agraphia as the sole detectable disorder of language organisation.

Pure agraphia-that is, the selective impairment of written communication-has rarely been described in the literature. Before 1960 , a number of authors (Wernicke, 1903; Henschen, 1922; Sinico, 1926; Morselli, 1930; Mahoudeau, 1950; Mahoudeau et al., 1951) reported cases of what they called pure agraphia which was caused by a lesion of the lower end of the second frontal convolution (F2). More recently, the assumption of a specific centre for writing in this part of the frontal lobe has been rejected (Leischner, 1969; Chedru and Geschwind, 1972). Since writing is a very complex function combining dyshomogeneous elements, it has been suggested that agraphia is of no clinical value for localisation of damage (Leischner, 1969). Some doubts have also been expressed concerning the existence of pure agraphia as an autonomous entity (Kreindler and Fradis, 1968). However, even though numerous questions on the significance of isolated writing disorders have not yet been answered, further evidence has been accumulated recently (Hécaen et al., 1963; Dubois et al., 1969; Assal et al., 1970; Aimard et al., 1975) to indicate that isolated writing disturbances do indeed occur in brain-damaged subjects. Unfortunately, these cases are characterised by a variety of both the nature and site of the cerebral lesions, and the language area was not always involved (Dubois et al., 1969).

In this report we describe the case of a right handed man who developed a disorder strictly

Address for correspondence and reprint requests: Dr G. Rosati, Clinica Neurologica dell'Università, Corso della Giovecca 203, 44100 Ferrara, Italy.

Accepted 17 August 1978 limited to written codification resulting from ischaemic damage to a discrete part of the language area.

\section{Case report}

A 62 year old, right handed farmer, ex-telegraphist, with a grade school certificate, was admitted to the Cardiovascular Division of Ferrara City Hospital in February 1977 for a recent myocardial infarction. On the morning of the eighteenth day in hospital on rising from the chair, he felt weakness of the right arm. A neurological examination showed only a slight right sided weakness of the face and arm. An EEG showed slowing of activity over the mid-regions of the left cerebral hemisphere. The right sided weakness recovered within about two hours. In the afternoon, re-examination showed no evidence of a motor deficit. The next morning, when attempting to write a letter, he realised he was writing nonsense. At this point he was transferred to the Neurological Clinic where he appeared alert and oriented to person, place, and time. Past and recent memory functions and knowledge of contemporary events, were intact. Forms I and II of the Weschler Memory Scale were used to assess verbal and non-verbal memory. For his command of contemporary events we asked the patient to answer questions about ongoing local events, current agricultural prices (relevant to his work as a farmer), and the like. Pupils, visual acuity, and visual fields were all normal. Ocular movements were full, with normal pursuit and saccadic versions. Arteriosclerotic changes in retinal vessels were present. The other cranial nerves were intact. Motor examination showed 
normal tone, strength, and co-ordination. The right and left sided tendon reflexes were equal. Primary sensory modalities, graphaesthesia, and stereognosis werc intact.

On testing higher cortical functions, a striking defect in ability to write was detected. Spoken speech and reading, as well as praxic, stereognostic (including fingergnosis), and perceptive functions, were found to be normal. For tests of language, the subject was given the Language Test constructed by the Neuropsychology Centre of the Neurological Clinic of the University of Milan (Copyright, Association for the Development of Neuropsychological Research, Milan, 1974). This test includes sections on expressive, receptive, and graphic abilities, as well as buccofacial apraxias. Examples of spontaneous writing and writing to dictation are shown in Fig. 1. There were numerous paragraphias, omission of vowels and consonants, transposition of letters in a word, repetition of letters and syllables, and repetition (perseveration) of words in a sentence (with omission of the first and more often the last syllables). Sometimes, an excess in the number of strokes in an individual letter was noted (for example, "uomini"). Ability to write numbers to dictation was preserved only for individual numbers. Copied writing was relatively conserved and not "imitative." Transcription of capital letters into lower case was correct about
$50 \%$ of the time. The alignment of writing on the paper was correct. His ability to transmit Morse code was tested with a tapping instrument, and he was severely impaired in transmitting signals with either the right or left hand. The only signal which was correctly transmitted was the one corresponding to "end of the transmission." The tapping of Morse signals was normally interpreted. On a test of block writing, no significant differences were found in comparison to handwriting, except that spelling appeared to be much less affected in this case. Sometimes during writing examinations he became discouraged and was unable to complete the task. On the Token test, which was administered in the short form (De Renzi and Faglioni, 1975), his score was 29 out of 36 . On the Wechsler Bellevue Intelligence Scale his verbal IQ was 95 and performance IQ 98, placing him at the division between normal and impaired in receptive ability.

No special hearing disorders were detected audiometrically.

During the next three weeks in hospital, the clinical picture remained unchanged. A comparison between protocols showed no significant improvement in neuropsychological performance. The EEG was repeated five times during this period and showed a persistence of localised damage in the region of the left temporal lobe.

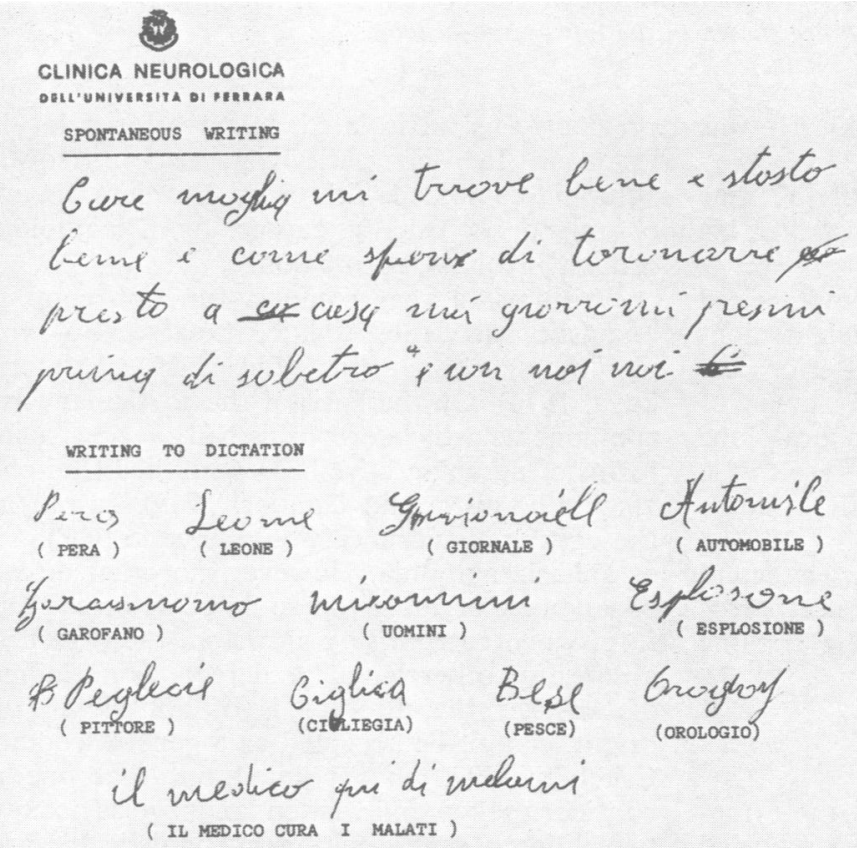

Fig. 1 Examples of spontaneous writing and writing to dictation showing numerous paragraphic elements. 

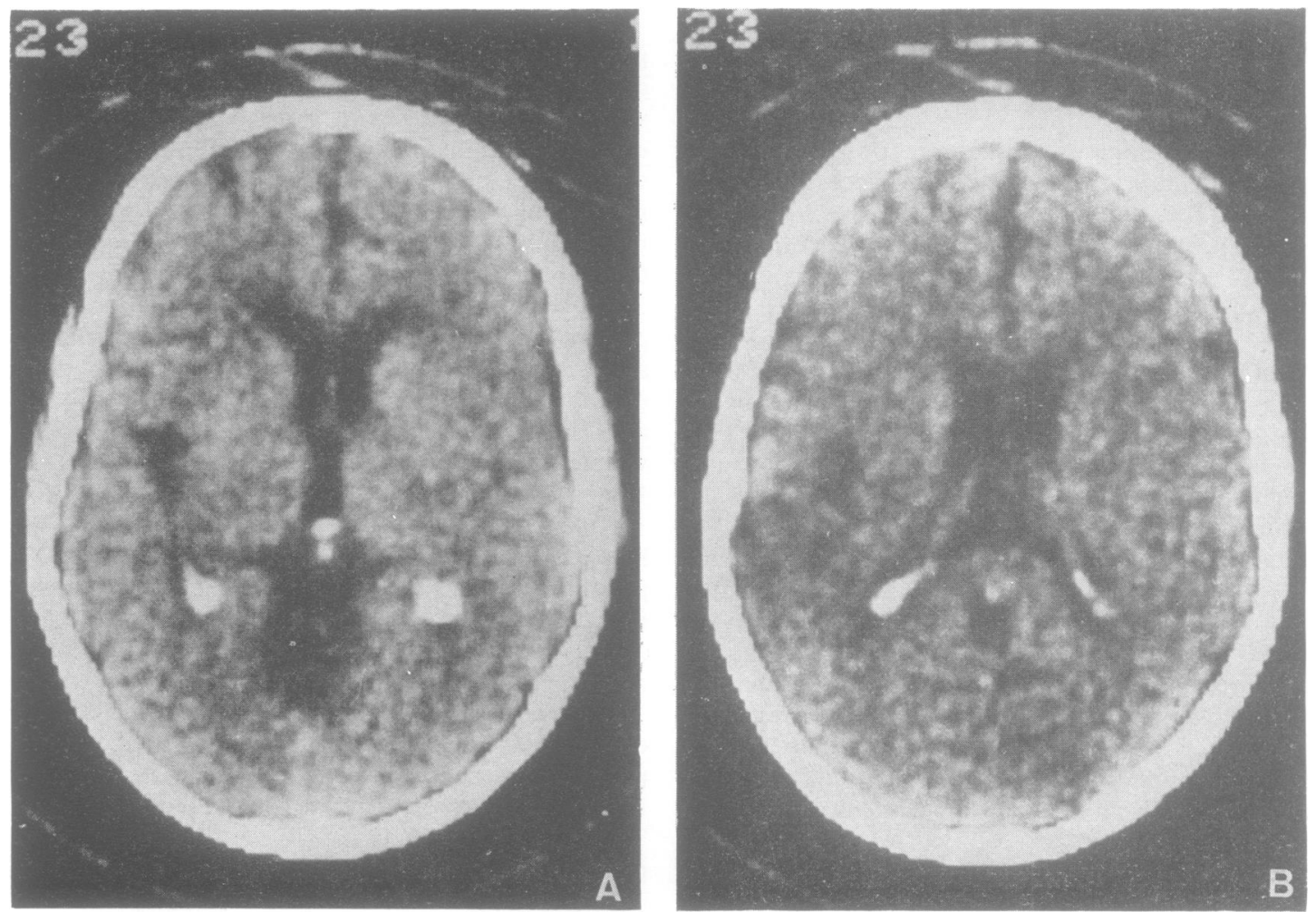

Fig. 2 Two consecutive $13 \mathrm{~mm}$ section; from inferior $(A)$ to superior $(B)$ from the CAT scan obtained four months after the ictus. At these levels there is widening of the posterior portion of the left Sylvian fissure. In $B$, patchy areas of diminished absorption are shown in the left temporal lobe.

The patient refused carotid arteriography. He was discharged after 10 weeks in hospital.

On follow up examinations in each of the four subsequent months, no changes were noted in his neuropsychological test scores.

Two months after leaving hospital, computerised axial tomography was carried out which demonstrated a left sided dilatation of the posterior portion of the Sylvian cistern and patchy areas of diminished absorption in the left temporal lobe (Fig. 2). These were interpreted as the result of a remote infarct in the territory of the middle cerebral artery.

Two months later, the patient sustained a second cerebrovascular accident, with sudden onset, gross right hemiplegia, and total aphasia. He became comatose and died four days later.

\section{Discussion}

To our knowledge, pure agraphia with the symptoms described in our case, has not been reported previously as an isolated defect after a localised lesion in the left perisylvian region. However, agraphia combined with other disorders, linguistic or mixed, is usually caused by a pathological process involving this region.

Writing is a very complex function combining linguistic, acoustic, praxic, kinaesthetic, visual. and motor components (Luria, 1973; Simernitskaya, 1974). On the basis of the particular writing components which are disturbed, various clinical forms of agraphia have been described (Leischner, 1969; Lhermitte and Gautier, 1969). In our case, the writing disturbance would have to be classified as aphasic agraphia. However, no other disorders of language organisation could be detected. Therefore, when categorising agraphia, the presence or absence of other language defects as an indicator of whether the disorder is of aphasic or other origin, cannot be accepted as a general condition. Critchley (1970) has pointed out that one may consider spoken and written language as occupying two different levels within a linguistic hierarchy. 
Writing is a language skill which is acquired relatively late, and written words are-to quote Jackson (1932) - "symbols of symbols." On this basis written language would be expected to be more vulnerable to disruption than spoken language. In a recent report on the initial and long-term effects of the left ("dominant") hemispherectomy for glioma (Burklund and Smith, 1977), it has been observed that writing, as a language function, is initially the most severely impaired and afterwards shows the least and slowest improvement. In other words, there are several reasons for considering that pure agraphia may exist as a discrete variety of aphasia.

The case described in the present report, in our opinion, leads to the conclusion that localised damage to the language area can produce a pure agraphia as the sole detectable disorder of language organisation, not just as a residual of a more general linguistic dysfunction but rather as an isolated deficit dating from the onset of illness.

We would like to thank Dr H. A. Buchtel for helpful comments on the manuscript.

\section{References}

Aimard, G., Devic, M., Lebel, M., Trcuillas, P.. and Boisson, D. (1975). Agraphie pure (dynamique?) d'origine frontal. Revue Neurologique, 131, 505512.

Assal, G., Chapuis, G., and Zander, E. (1970). Isolated writing disorders in a patient with stenosis of the left internal carotid artery. Cortex, 6, 241-248.

Burklund, C. W., and Smith, A. (1977). Language and the cerebral hemispheres: observations of verbal and nonverbal responses during 18 months following left ("dominant") hemispherectomy. Neurology (Minneapolis), 27, 627-633.

Chedru, F., and Geschwind, N. (1972). Writing disturbanzes in acute confusional state: Neuropsychologia, 10, 343-353.

Critchley, M. (1970). A phasiology and Other Aspects of Language. Edward Arnold: London.

De Renzi, E., and Faglioni, P. (1975). L'esame dei disturbi afasici di comprensione orale mediante una versione abbreviata del test dei gettoni. Rivista di Patologia Nervosa e Mentale, 96, 252-269.

Dubois, J., Hécaen, H., and Marcie, P. (1969). L'agraphie "pure". Neuropsychologia, 7, 271-286.

Hécaen, H., Angelergues, R., and Douzens, J. A. (1963). Les agraphies. Neuropsychologia, 1, 179-208.

Henschen, E. S. (1922). Klinische und anatomische Beiträge zur Pathologie des Gehirnes. VII. Über motorische Aphasie und Agraphie. E. S. Henschen: Stockholm.

Jackson, J. H. (1932). Selected Writings. Edited by J. Taylor. Hodder and Stoughton: London.

Kreindler, A., and Fradis, A. (1968). Performances in Aphasia. Gauthier-Villars: Paris.

Leischner, A. (1969). The agraphias. In Handbook of Clinical Neurology, vol. 4, pp. 141-180. Edited by P. J. Vinken and G. W. Bruyn. North Holland: Amsterdam.

Lhermitte, F., and Gautier, J. C. (1969). Aphasia. In Handbook of Clinical Neurology, vol. 4, pp. 84104. Edited by P. J. Vinken and G. W. Bruyn. North Holland: Amsterdam.

Luria, A. R. (1973). The Working Brain. Penguin Books: London.

Mahoudeau, D. (1950). Considérations sur l'agraphie, à propos d'un cas observé chez un traumatisé du crâne porteur d'une lésion des deuxième et troisième convolutions frontale gauches. Sémaine des Hôpitaux (Paris), 26, 1598-1601.

Mahoudeau, D., David M., and Lecoeur, J. (1951). Un nouveau cas d'agraphie sans aphasie révélatrice d'une tumeur métastatique du pied de la deuxième circonvolution frontale gauche. Revue Neurologique, 1, 159-161.

Morselli, G. E. (1930). A proposito di agrafia pura. Rivista Sperimentale di Freniatria, 54, 500-511.

Simernitskaya, E. G. (1974). On two forms of writing defect following local brain lesions. In Hemisphere Function in the Human Brain. Edited by S. J. Dimond and J. G. Beaumont. Elek Science: London.

Sinico, S. (1926). Neoplasia della seconda circonvoluzione frontale sinistra: agrafia pura. Gazzetta degli Ospedali e delle Cliniche (Milano), 47, 627631.

Wernicke, C. (1903). Ein Fall von isolierter Agraphie. Monatsschrift für Psychiatrie und Neurologie, 13, 241-265. 